\title{
RESEARCH ACTIVITIES OF EPIDEMIOLOGY IN JAPAN
}

\author{
Environmental Health
}

\author{
Kazuho Maeda ${ }^{1}$ and Hiroshi Nitta ${ }^{2}$
}

\begin{abstract}
The rapid industrial development that began in the 1950's created environmental problems which consequently led to health hazards among residents of heavily polluted areas in Japan, such as Minamata Disease and Yokkaichi Asthma. Faced with these situations, the Japanese national government and local environmental authorities exerted much efforts to control pollution as well as to provide solutions to health problems. Many studies, including environmental epidemiology, have been conducted, aiming at determining relations between health problems and pollution. The results of environmental epidemiologic studies were prone to conclude associations with pollution and targeted health damages. In the case of the air-pollution related diseases, the government compensated individuals with non-specific respiratory diseases who are residents in the designated special high level air pollution areas. Epidemiological studies played an important role in designating pollution-related diseases and polluted areas.
\end{abstract}

J Epidemiol, 1996 ; 6 : S121-S124.

environmental epidemiology, pollution-related diseases, NAAQS

\section{INTRODUCTORY REMARKS}

The rapid industrial development that began in the 1950's created environmental problems which consequently led to health hazards among residents of heavily polluted areas in Japan. Among health-related problems were chronic respiratory diseases due to exposure to high concentrations of variuos contaminants in air, and intoxication of metals such as organic mercury, arsenic and cadmium in water.

Minamata Disease was caused by the ingestion of methylmercury compound which was discharged from a chemical plant along with industrial waste water and accumulated in fish and/or shellfish via the food chain. Epidemiological surveys revealed that Minamata Disease patients were mostly fishermen and their families who consumed much of those fishes ${ }^{1}$.

One of the most serious air pollution problems occurred in Yokkaichi City in which a petroleum and petrochemical complex was established in the 1950's. This complex was surrounded by many residential districts. Because of the high incidence of asthmatic disorders among nearby residents, epidemiologist investigated the relationship between air pollution levels and the morbidity of respiratory diseases and pointed out an increased prevalence of chronic bronchitis among residents in those districts.

Faced with these situations, the Japanese national government and local environmental authorities exerted much efforts to control pollution as well as to provide solutions to health problems. Many studies, including environmental epidemiology, have been conducted, aiming at determining relations between health problems and pollution. Supported from general public against pollution, especially against pollution related health damages, the results of environmental epidemiologic studies were prone to conclude associations with pollution and targeted health damages, and these conclusions were often urged to address the existence of causal relationship between pollution exposure and health damages. This kind of tendency had influenced epidemiological researches until recent years and was strengthened by public opinion against pollution.

In the past, since the methodology for environmental epidemiology, in particular for exposure assessment was unsatisfactory, epidemiologists had to use surrogate method for the determination of indices of exposure levels. In air pollution studies, long-term averaged values of nearby air monitoring site were used, although it was not realized that those did not express real and/or correct individual exposure.

\footnotetext{
Received and accepted December 4, 1995.

${ }^{1}$ Tokyo Kasei University, Tokyo, Japan.

${ }^{2}$ National Institute for Environmental Studies, Tsukuba, Japan.

Address for correspondence : Kazuho Maeda, Tokyo Kasei University, 1-18-1 Kaga Itabashi-ku Tokyo, 173 Japan.
} 


\section{POLLUTION CONTROL HISTORY IN JAPAN}

As described above, the Japanese Government has concentrated its efforts on reducing ambient $\mathrm{SO}_{2}$ concentration which is emitted from fossil fuel combustion. In 1971, the Japanese Government established the Environment Agency (EA) which coordinates and plans strategies for pollution control and environmental conservation, and provides solutions to health problems ${ }^{2)}$. The EA pushed strongly pollution control in terms of setting the most stringent air and water quality standards for several pollutants and the emission limit of automobile exhaust gases. In order to cope with health problems, the EA issued the Pollution-Related Health Damages Compensation Law based on the PPP ( polluter pay principle), which stipulates that compensation must be paid to individuals suffering from pollution-related health problems who have been recognized through an administrative procedure. The government has designated four air-pollution-related diseases and three water-pollution-related diseases. In the case of the air-pollution related diseases, the government compensated individuals with nonspecific respiratory diseases (chronic bronchitis, bronchial asthma, asthmatic bronchitis, pulmonary emphysema) who are residents in the designated special high level air pollution areas. Epidemiological studies played an important role in designating pollution-related diseases and polluted areas. It is but natural friction occurred between government and industry in the process of enforcement of stringent control measures against pollution. As the consequences of strict pollution control, air pollution levels in highly polluted areas were suppressed to meet national air quality standards in the late 1970's.

\section{REVISION OF STRINGENT NAAQS AND COMPENSATION LAW}

In 1978, the EA revised the ambient air quality standard for $\mathrm{NO}_{2}$ to within the range of 0.04 to $0.06 \mathrm{ppm}$, or below, in terms of daily average, to replace the old standard of "not more than $0.02 \mathrm{ppm}$ in terms of daily average".

Soon after the revision, the EA organized a task force to investigate air pollution and health effects. With the aim of reducing air pollution in the 1980's, the EA conducted two nationwide epidemiological surveys to study the relationship between air pollution and health effects. After investigations conducted over a period of one year, the task force concluded that air pollution levels still had some effects on people's health, but the effects were not the same as those observed during the period of markedly high levels of pollution. Based on the conclusions reached by the task force, the Central Council on Environmental Pollution Control Measures recommended the EA that the Pollution-Related Health Damage Compensation Law be revised in part. The recommendations included four points : (1) lifting the designations on highly polluted areas, (2) continued compensation to the certified patients, (3) implementation of comprehensive measures for environmental health protection, and (4) intensified measures for the prevention of air pollution. Based on these recommendations, the EA revised the Compensation Law abiding by the conclusion of the Council ${ }^{3}$. In the process of inducing the conclusion of the task force, it referred to the two epidemiological surveys, which used a Japanese version of the ATS-DLD questionnaire. Those surveys concentrated on checking the exposure levels to pollution, especially to $\mathrm{NO}_{2}$. The surveys had some limitations, however, they adopted principal items of environmental epidemiology, especially exposure analysis.

\section{RECENT MAJOR TOPICS IN THE FIELD OF ENVIRONMENTAL EPIDEMIOLOGY IN JAPAN}

In Japan, many residences in large cities front onto major roadways which have become extremely congested because of the increasing number of motor vehicles in use and the increasing volume of traffic. The EA estimates that more than four millions people live within one hundred meters from major roadways in Tokyo. As far as NOx emitted from motor vehicles is concerned, strict regulations have been put into effect since 1973. Nevertheless, in recent years there are still many air monitoring stations which have shown higher levels of NOx than the Ambient Air Quality Standard. Researchers and policy makers recognize that the assessment of potential impacts of gases and particles emitted from automobiles on health is an important task.

Thus, several cross-sectional studies have been conducted on respiratory conditions of residents living nearby the major roads in Tokyo, where there is consistently heavy traffic (Table $1)^{4-10)}$. Those studies assess exposure to automobile exhaust and the relationships between the prevalence of respiratory symptoms and location of residence with respect to distances from the roadside. Although designs were slightly different among the studies, respiratory health and exposure levels were basically compared among residents divided into two or three zones according to the distance of the their homes from the roadside. All of the studies included respiratory symptoms surveys in female adults. The assessment of respiratory symptoms in subjects was made by a standard self-administrated questionnaire which was a modified Japanese version of the ATS-DLD-78 questionnaire.

The gradients of $\mathrm{NO}, \mathrm{NO}_{2}$ and $\mathrm{PM}$ outdoor concentrations suggest that residents living in homes near the roadside are likely to be exposed to higher levels of automobile exhaust. The indoor and personal exposure levels to the pollutants, however, varied among the surveys. The surveys also took into consideration the contribution of indoor sources, such as tobacco smoking and combustion appliances. Even the large contributions of indoor sources, indoor $\mathrm{NO}_{2}$ and indoor $\mathrm{PM}$ levels were likely to decrease with distance from the roadside. The results support the use of the proximity to road traffic as an exposure variable. There is a possibility of misclassification of the exposure levels in those studies. In many cases, especial- 
Table 1. Summary of study areas

\begin{tabular}{|c|c|c|c|c|}
\hline survey period & area & major roads & $\begin{array}{l}\text { zone for distance } \\
\text { from the roadside }\end{array}$ & $\begin{array}{l}\text { traffic } \\
\text { volume } *\end{array}$ \\
\hline \multirow[t]{2}{*}{ October, 1979} & $\begin{array}{l}\text { Itabashi, Nerima \& } \\
\text { Nakano Ward }\end{array}$ & $\begin{array}{l}\text { Kannana-dori } \\
\text { Avenue }\end{array}$ & $\begin{array}{r}0-20 \mathrm{~m} \text { (zone } 1) \\
20-150 \mathrm{~m} \text { (zone } 2)\end{array}$ & 44,000 \\
\hline & Hachioji City & Route 20 & $\begin{array}{r}0-20 \mathrm{~m} \text { (zone } 1) \\
20-150 \mathrm{~m} \text { (zone } 2)\end{array}$ & 14,000 \\
\hline October, 1982 & Itabashi \& Kita Ward & $\begin{array}{l}\text { Kannana-dori } \\
\text { Avenue \& Route17 }\end{array}$ & $\begin{array}{c}0-20 \mathrm{~m} \text { (zone } 1) \\
20-150 \mathrm{~m} \text { (zone } 2 \mathrm{a}) \\
50-150 \mathrm{~m} \text { (zone } 2 \mathrm{~b})\end{array}$ & 53,000 \\
\hline October, 1983 & $\begin{array}{l}\text { Suginami \& Nerima } \\
\text { Ward, Hoya \& Tanashi City }\end{array}$ & Ome-kaido Avenue & $\begin{array}{r}0-20 \mathrm{~m} \text { (zone } 1) \\
20-150 \mathrm{~m} \text { (zone } 2)\end{array}$ & 30,000 \\
\hline November, 1986 & Katsushika Ward & $\begin{array}{l}\text { Kannana-dori } \\
\text { Avenue \& Route } 6\end{array}$ & $\begin{array}{c}0-20 \mathrm{~m} \text { (zone } 1) \\
20-150 \mathrm{~m} \text { (zone } 2 \mathrm{a}) \\
50-150 \mathrm{~m} \text { (zone } 2 \mathrm{~b})\end{array}$ & 35,000 \\
\hline $\begin{array}{l}\text { July, } 1987 \text { to } \\
\text { february, } 1990\end{array}$ & Sumida Ward & $\begin{array}{l}\text { Meiji-dori } \\
\text { Avenue \& Route } 6\end{array}$ & $\begin{array}{r}0-20 \mathrm{~m} \text { (zone } 1) \\
20-150 \mathrm{~m} \text { (zone } 2)\end{array}$ & 30,000 \\
\hline
\end{tabular}

* vehicles per 12 hrs in daytime

ly nondifferential cases, however, misclassification results in a bias toward no effects.

Prevalences of chronic cough and chronic phlegm were shown to be different among the exposure groups in most of the surveys. Although the estimates of odds ratios for chronic cough and chronic phlegm varied across the studies, the results of meta-analysis suggested that respiratory symptoms might be associated with automobile exhaust. Odds ratios for chronic cough and chronic phlegm in all studies exceeded the value of 1.0 except for one study. The estimates of the combined odds ratios was approximately 1.5 (Fig. $1 \& 2$ ). There seemed to be differences in respiratory symptoms among residents of the surveyed areas as well as among residents of the different zones of distance from the road. Those differences might be due to air pollution from stationary sources rather than mobile sources. Consequently, we could not consider the differences

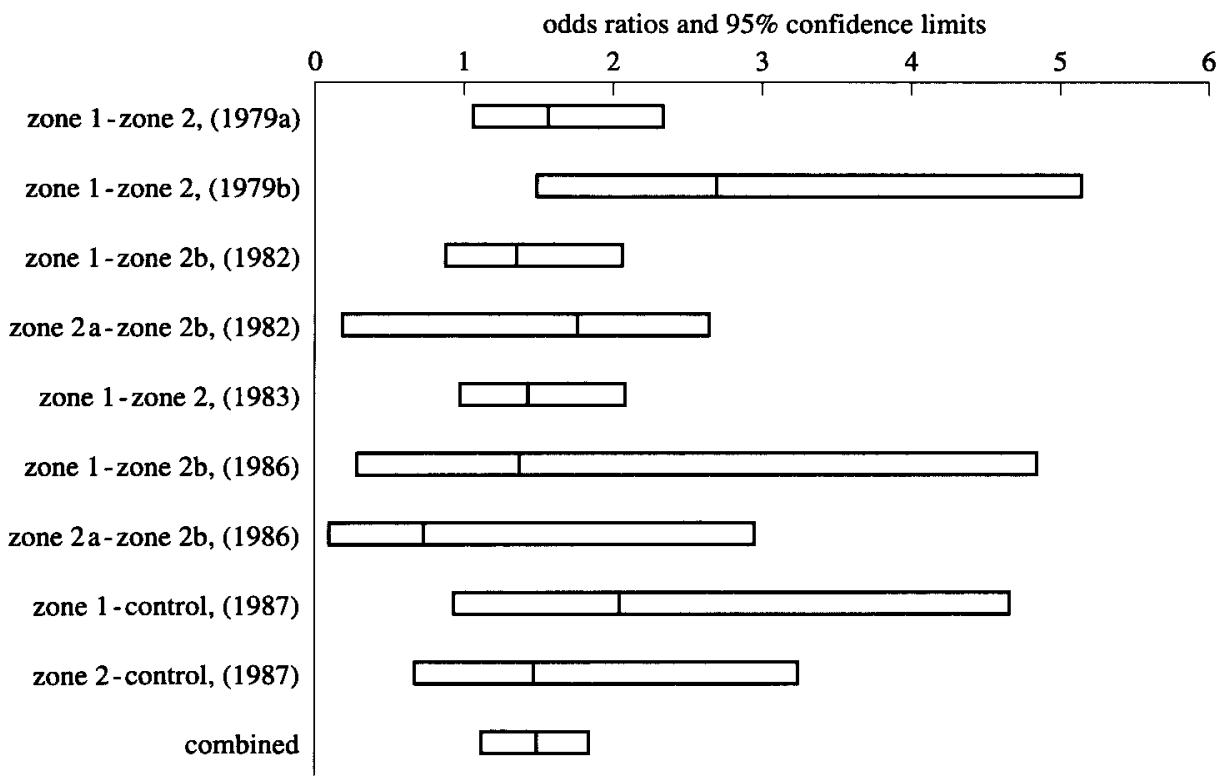

Figure 1. Summary of odds ratios for chronic cough adjusted by age and smoking status 


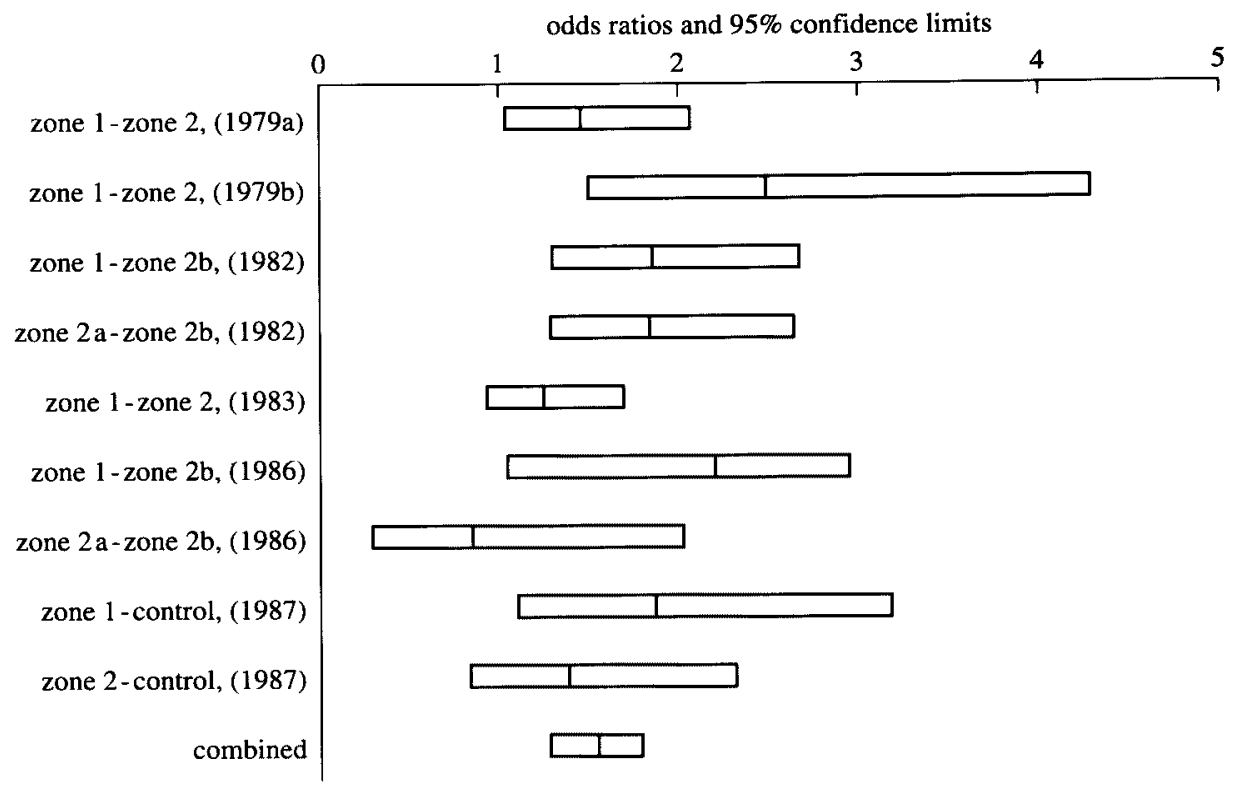

Figure 2. Summary of odds ratios for chronic phlegm adjusted by age and smoking status

in respiratory symptoms among the exposure groups as spurious effects.

\section{FUTURE PERSPECTIVES}

Not only in Japan but all over the world, concern on global environment problems becomes greater year by year. The study method most applicable to solving global environmental problems is environmental epidemiology. In Japan, interest in environmental epidemiology methods is growing, with many Japanese epidemiologists attending the international meeting organized by ISEE/ISEA (International Society of Environmental Epidemiology and International Society of Exposure Analysis). The results of their studies were presented, and discussions were held. With these positive signs, we believe that in the near future, studies relating environmental epidemiology in Japan with those in other countries will be realized.

\section{REFERENCES}

1. Environmental Health Department, Environment Agency of Japan. Our intensive efforts to overcome the tragic history of Minamata Disease, 1994.

2. Nishimura $\mathrm{H}$, ed. How to conquer air pollution : A Japanese Experience, Elsevier, Amsterdam, 1989.

3. Environment Agency of Japan, Japan Environment Summary, vol.15, no.10, 1987.
4. Nitta $\mathrm{H}$, Ono $\mathrm{M}$, et al. Respiratory symptoms among residents living closely along major traffic arterials in Tokyo, Jpn. J. Public Health, 1983 ; 30 : 381-389.

5. Nitta H, Sato T, et al. Cross-sectional studies of respiratory symptoms in female adults associated with exposure to automobile exhaust. Jpn. J. Public Health, $1989 ; 36$ : 220-227.

6. Ono M, Murakami M, et al. Epidemiological studies of air pollution and health effects in areas near roadways with heavy traffic in Tokyo. Jpn. J. Public Health, 1990 ; $37: 321$.

7. Maeda K, Nitta H, Nakai S. Exposure to Nitrogen Oxides and Other Air Pollutants from Automobiles. Public Health Review, 1991/1992 ; 19:61-72.

8. Nitta H, Sato T, Nakai S, Maeda K, Aoki S, Ono M. Respiratory Health Associated with Exposure to Automobile Exhaust. 1. Results of Cross-sectional Studies in 1979, 1982, and 1983. Archives of Environmental Health, $1993 ; 48$ : 53-58.

9. Maeda K, Nitta H, Ono M, Nakai S. Meta-Analysis in Studies of Health Effects of Local High Air Pollution. The 7th IUAPPA Regional Conference on Air Pollution and Waste Issues, Taipei, 1994.

10. Nakai S, Nitta H, Maeda K. Respiratory Health Associated with Exposure to Automobile Exhaust. II. Personal $\mathrm{NO}_{2}$ levels according to distance from the roadside. J Exposure Analysis and Environmental Epidemiology, 1995 ; 5 : 125-136. 